\title{
THE EFFECT OF MISWAK VARNISH ON STREPTOCOCCUS MUTANS COUNT AND GINGIVAL INFLAMMATION IN ORTHODONTIC PATIENTS
}

\author{
Sherief H. Abdel-Haffiez ${ }^{\mathrm{a}}$; Tarek N. Yousry ${ }^{\mathrm{a}}$; Mohamed I. Mowafy ${ }^{\mathrm{b}}$
}

\section{A6stract}

Objective:

Primary objective: To evaluate the effect of Miswak extract varnish on streptococcus mutans (S.mutans) counts in saliva and plaque, gingival bleeding index (GBI) and plaque index (PI) in orthodontic patients. Secondary objective: to suggest an appropriate frequency Miswak varnishes application to produce maximum efficiency.

Material and methods:

Enrolled patients $(n=75)$ were randomly and equally divided into 3groups. Chlorhexidine varnish group, Miswak varnish group and control group. S.mutans counts in plaque and saliva, GBI and PI were evaluated at different time points; T0: before brackets bonding, T1: two weeks after brackets bonding, T2: one months after brackets bonding and $\mathcal{T}_{3}$ : three months after brackets bonding.

Results:

Both chlorhexidine and Miswak varnishes reduced plaque S.mutans counts significantly at $\mathcal{T} 2$ compared to the controls, with no significant difference between Chlorhexidine and Miswak varnishes at this timepoint. After 3 months, chlorhexidine varnish group had the lowest S.mutans plaque counts followed by Miswak varnish group, while the control group had the highest counts. GBI was reduced significantly in 6oth chlorhexidine and Miswak varnishes groups, when compared to the control group at 6oth one month and 3 months timepoints with no statistically significant differences between chlorhexidine and Miswak, neither at one month nor at 3 months. PI showed no statistically significant differences between the 3 study groups at different timepoints.

Conclusions:

Miswak varnish can be an acceptable natural substitute to chlorhexidine varnish as an anticariogenic agent if applied at monthly basis. Mechanical brushing is mandatory to reduce plaque accumulation and maintain proper gingival health.

\section{Introduction}

White spot lesions (WSL) are a common side effect in $50 \%$ to $70 \%$ of patients undergoing fixed orthodontic appliances treatment(1).The cause of these lesionsis multifactorial, mainly caused by the inability to maintain proper oral hygiene together with $\mathrm{pH}$ levels lower than 4.5 recorded in the plaque around fixed orthodontic appliances components(2). Moreover, Orthodontic treatment may induce disturbances of the complex oral ecosystem leading to an increase in cariogenic microorganisms such as Streptococcus mutans (S.mutans) in saliva(3$5)$.

Chlorhexidine has the ability to prevent and reduce bacterial growth(6) and consequently inhibit acid production and $\mathrm{pH}$ falls in plaque(7); therefore, chlorhexidine is considered the gold standard to inhibit enamel demineralization(6,8-11). However, prolonged use of chlorhexidine preparations may have adverse side effects on oral structures such as; mucosal irritation and burning sensation, bitter taste, , teeth discoloration and tongue staining(12,13).Moreover, S.mutans and the other oral microorganisms have developed

\footnotetext{
${ }^{a}$ Lecturer, Department of Orthodontics, Faculty of Dentistry, Alexandria University, Alexandria, Egypt

${ }^{\mathrm{b}}$ Assistant professor, Department of Orthodontics, Faculty of Dentistry, Alexandria University, Alexandria, Egypt

Corresponding author: Sherief H. Abdel-Haffiez, email : sherief_hussein@hotmail.com
} 
resistance to chlorhexidine due to its routine use in dental care products(14).

Recently, the use of natural plant extracts for dental caries controlhas been increasing as they are economical and with no apparent side effects(15). Studies tested different plants with different preparation methods and results were always promising(16-18).World Health Organization (WHO) recommends the use of chewing sticks obtained from natural plants due to its promising results in promoting oral health(19).Among 182 species of natural plants used for this purpose worldwide,Salvadora persica plant (the commonly known as miswak tree) is the most commonly used plant for this practice(20).A wide variety of oral health promoting organic and inorganic components have been isolated from miswak extract(21)and researches found it to have antiplaque(22), antibacterial $(23,24)$ and consequently anticariogenic(25) properties. Miswak extract showed potential antibacterial activity against S.mutans and Lactobacillus acidophilus(26). Miswak use resulted in better periodontal status than normal toothbrush (27); due to its inherited antibacterial activity against cariogenic and periodontopathic bacteria(28).

To our knowledge, few studies have investigated the antibacterial effect of Miswak extract in orthodontic patients. The primary aim of this study was to evaluate the effect of Miswak extract varnish on streptococcus mutans counts in saliva and plaque, gingival bleeding index (GBI) and plaque index (PI) in patients undergoing fixed orthodontic appliance therapy in comparison to a varnish containing the chlorhexidine gold standard. The secondary aim is to suggest an appropriate frequency for chlorhexidine or Miswak varnishes application to produce maximum efficiency.

\section{Material and methods}

Study design: Prospective randomized controlled clinical study.

Study sample: Consisted of patients assigned to start fixed orthodontic appliance treatment in the department of Orthodontics, Faculty of Dentistry, Alexandria University. Investigators supplied the patients or their guardians (for patients younger than 18 years old) with full detailed information about the study procedures and aim.An informed consent was signed for every participant before being involved in the study. The investigators had the study protocol approved from the ethics committee in Faulty of Dentistry, Alexandria University.

Sample size estimation, randomization, and grouping:

Based on the results obtained from a pilot study and with parameters set at; alpha error $\leq 0.05$, power of 0.8 and 1 degree of freedom; the minimum number of participants was calculated at 23 per group. Therefore, 75 participants ( 25 per group) were included in the study according to the following criteria:

- Age ranges from 14 years to 20 years

- Nonsmokers

- Healthy with no general illness or systemic disease

- No mental or physical disabilities

- No extensive dental restorations, noactive carious lesions, or missing teeth due to caries

- Good periodontal condition with no existing periodontal disease

- Lack of use of antibiotics for the last 3 months

- Fully erupted permanent dentition with at least 20 permanent teeth bonded with orthodontic attachments.

\section{- Female patients}

Participants were equally and randomly (according to a computer-generated 
randomization table) allocated in one of 3 groups:

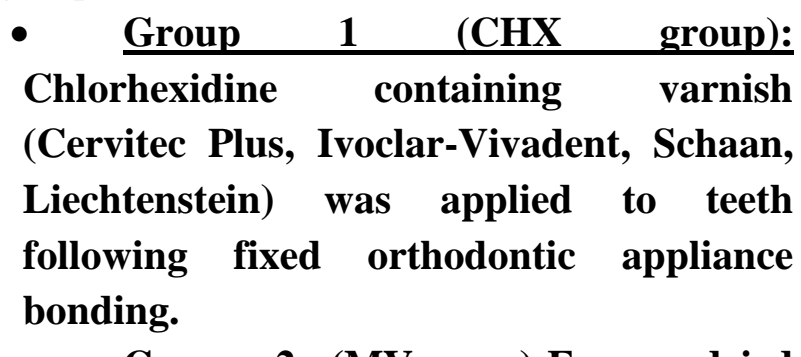

- $\quad$ Group 2 (MVgroup):Freeze dried aqueous miswak extract varnishwas applied to the teeth following fixed orthodontic appliance bonding.

- Group 3 (Control group): With no varnish or further treatments applied to the teeth.

\section{Blinding:}

Patients were blinded to the which group they belong and blinded to the content of the varnish applied. Saline was applied to the teeth after bonding in the control group as a placebo in a manner similar as varnishes were applied in the other 2 groups, so patients were not conscious about differences in the procedures between different groups. Saliva and plaque samples were collected by one investigator, while plaque index (PI) and gingival bleeding index (GBI) were recorded by another investigator. Both investigators were blinded to study groups. Microbiology specialist: who performed bacterial culture procedures and bacterial colonies counting; was also blinded to different groups. Intraexaminer reliability was tested for individuals performing PI, GBI and bacterial colonies counting following the (WHO) [2013] guidelines (mean kappa values were 0.87, 0.89 and 0.86 respectively).

\section{Miswak varnish preparation(29):}

Freshly cut Miswak sticks were obtained from Arak (Salvadora persica) trees in Saudi Arabia. Obtained sticks were sundried and ground. Ten grams of ground sticks were soaked in $100 \mathrm{~mL}$ of sterile distilled water for
$48 \mathrm{~h}$ at $4^{\circ} \mathrm{C}$. This mixture was then centrifuged and filtered to produce aqueous Miswak extract. The resultant extract was then freeze dried for 7 days in a freeze drying machine to produce freeze dried aqueous Miswak extractpowder.A mixture of 10 grams of prepared freeze dried aqueous Miswak extract powder, $75 \mathrm{~mL}$ of $95 \%$ ethanol (solvent), $25 \mathrm{ml}$ Distilled deionized water, and 20 grams of Colophony resinwas left over night to dissolve and produce "Freeze dried aqueous Miswak extract varnish".

\section{Study procedures:}

Each eligible patient received professional dental scaling and prophylaxis 3 weeks prior to fixed orthodontic appliance bonding.

All the patients in all the study groups were instructed to follow routine oral hygiene measures. All the patients were provided the same commercially available toothpaste, toothbrush and mouthwash and were asked to use the same toothpaste and mouthwash provided to them throughout the whole study period. Demonstrations for proper oral hygiene practices were given to all the patients initiallyand were emphasized on every followup appointment.

Metal orthodontic brackets and tubes (UnitekGemini brackets, 3M Unitek Orthodontic Products) were bonded to the buccal surface of the teethusing nonfluoridatedcomposite (Unite; 3M Unitek, Monrovia, Calif).

Varnishes were applied to the teeth on interproximal surfaces and labial surfaces around orthodontic brackets and tubes immediately after bonding using applicator brush (Figure 1) and allowed to dry for 1 minute. Patients were instructed to refrain eating,drinking, or rinsing for 2 hours and not to brush their teeth for 24 hours. 


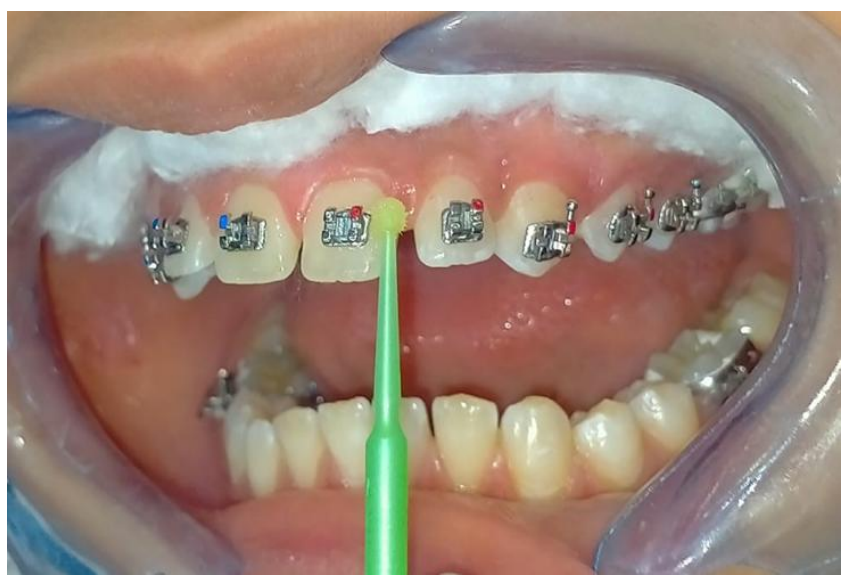

Figure 1. Varnish application to maxillary teeth using microbrush applicator immediately after upper arch bonding.

Plaque index (PI)(30) and Gingival bleeding index (GBI)(31) scoring:

Teeth and gingiva were gently and lightly dried using a gentle stream of air after partial isolation using cotton rolls in buccal and lingual sulci. Six index teeth were used for PI and GBI scoring in each patient; maxillary right first molar, maxillary right lateral incisor, maxillary left first bicuspid, mandibular left first molar, mandibular left lateral incisor and mandibular right first bicuspid.

The four surfaces of each index tooth (buccal, lingual, mesialand distal) were evaluated.

For PI scoring each surface was given a score 0-3 as follow,

\section{- $\quad$ Score 0: No plaque}

- Score 1: A film of plaque adhering to the free gingival margin and/oradjacent area of the tooth. The plaque may not be seenby naked eye but is visibleonly after application of disclosing solution or after wiping the surface with a probe.

- Score 2: Moderate accumulation of soft deposits within the gingivalpocket, or on the tooth aroundgingival margin which can be seen with the naked eye.
- $\quad$ Score 3: Abundance of soft matter within the gingival pocket and/or on the tooth and gingival margin

The score obtained from each surface of a tooth was recorded, and the four scores for each tooth were summed and then divided by four to give the PI for the tooth.The PI for the patient was obtained by summing the indices recorded for the examined teeth in each patient and dividingthemby six.

For GBI scoring, a $0.5-\mathrm{mm}$ periodontal probewas gently inserted into the gingival crevice until the attachment epithelium was reached and then moved gently along the crevice parallel to the long axis of the tooth with no apical force to avoid tissue penetration. The gingival margin of the four surfaces of each index tooth was evaluated for bleeding and score 1 was given if bleeding was detected and score 0 was given for non-bleeding sites. GBI was calculated as the number of bleeding surfaces relative to total number of examined surfaces.

\section{Plaque and saliva sampling for bacterial cultures(32):}

Patients were instructed to refrain from oral hygiene procedures for 24 hours and not to consume foods or drinks (except water) for at 
least 2 hours before each sampling appointment.Salivary samples collection was performed before any manipulation of the orthodontic appliance so as not to disrupt the oral microbiotic environment. Each patient was instructed to chew an enclosed paraffin pellet for 30 seconds, and then was asked to remove the produced saliva.Then, the paraffin pellet was readministered, asking the patient to chew it for 30 seconds and collect the produced saliva in a small sterile test tube for 5 minutes. This could produce around $3 \mathrm{~mL}$ of saliva.

Before plaque sampling, patients were instructed to swallow to reduce amount of saliva in the patients' mouth, and a gentle stream of air was used to remove saliva remnants on the teeth. Partial isolation was done using cotton rolls, and care was given to avoid any contamination of blood or saliva during plaque sampling. Plaque samples were collected from all accessible areas around the brackets of central incisor, canine, second premolar and first permanent molar in each quadrant using a sterile wooden dental wedge (Figure 2). The tips of the used wooden wedge with adherent plaque were cut off and transferred to sterile screw-capped test tube with $1.0 \mathrm{~mL}$ transport fluid (33).

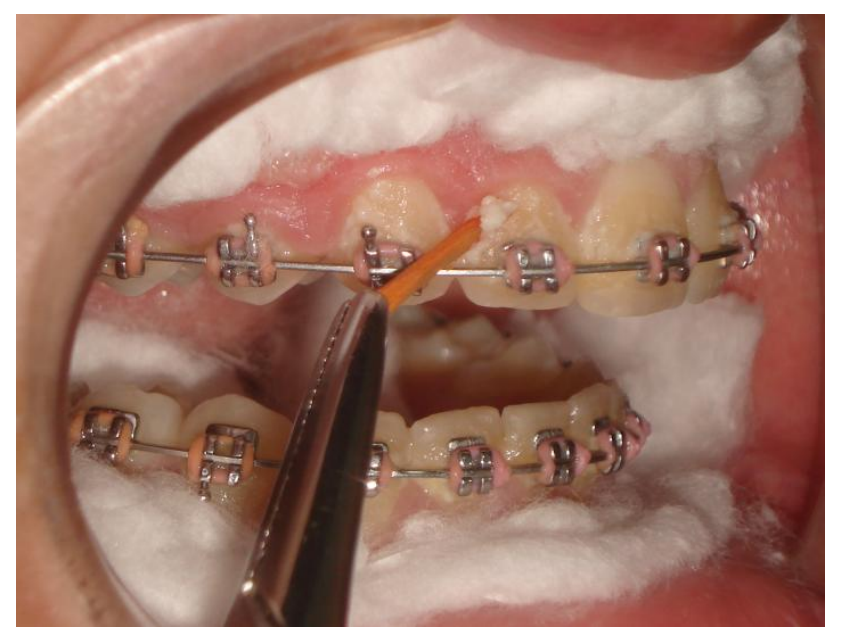

Figure 2. Plaque sampling for culture using a sterile wooden wedge.

Plaque and saliva samples were sent to the Microbiology department, Faculty of Medicine, Alexandria University immediately after collection and were processed within one hour.One $\mathrm{mL}$ of the collected saliva sample was transferred to $5.7 \mathrm{~mL}$ of the transport medium and dispersed in a centrifuge for 30 seconds before it was plated on mitis salivarius-bacitracin (MSB) agar.(34)Plaque samples were homogenized by sonication for 10 seconds and diluted in $0.05 \mathrm{M}$ phosphate buffer and $25 \mu 1$ portions of diluted plaque were collected and spread on MSB agar.
The agar plates were incubated in anaerobic atmosphere $95 \% \mathrm{~N}$ and $5 \% \mathrm{CO}_{2}$ at $37^{\circ} \mathrm{C}$ for 48 hours (35). After 48 hours of incubation, the S. Mutanscharacteristic colonies were identified as small, rough, raised and adherent colonies (36)and for further confirmation,representative colonies were checked by immunofluorescence (37). The number of colony-forming units (CFU) of S. mutans werecounted using an electronic colony counter. 


\section{Study periods}

PI, GBI and CFU of salivary and plaque S. mutans were recorded for each patient in the following points

- T0 :Baseline,Immediately before fixed appliance bonding (at same visit of bonding).

- T1: After 2 weeks of bonding.

- T2 :One month after fixed appliance bonding.

- T3 :Three months after fixed appliance bonding.

\section{Statistical methodology}

Normality was checked for all variables using descriptive statistics, plots, and Kolmogorov-Smirnov normality test. All variables showed normal distribution, so means and standard deviations (SD) were calculated, and parametric tests was used. Comparisons between the three study groups were done using one-way ANOVA, while comparisons between different timepoints within each group were done using repeated measures ANOVA. Both tests were followed by multiple pairwise comparisons using Bonferroni adjusted significance levels (for statistically significant differences only). Significance was inferred at $\mathrm{p}$ value $<0.05$. Data were analyzed using IBM SPSS for Windows (Version 23.0) (IBM Corp. Released 2013. IBM SPSS Statistics for Windows, Version 22.0. Armonk, NY: IBM Corp.)

\section{$\underline{\text { Results }}$}

The results of this study showed a significant increase in streptococcus mutans count in plaque and saliva following fixed appliance bonding in all the study subjects. Also bonding of fixed appliances resulted in significant increase in GBI and in PI in all the study subjects. No significant differences were observed between the study groups at baseline nor at $\mathrm{T} 1$ (after brackets bonding) in any of the studied parameters.

\section{S.mutans count in plaque:}

Both chlorhexidine and Miswak significantly reduced S.mutans counts in plaque after one month following a single application. No significant difference was observed between chlorhexidine and Miswak effect after one month. However, the control group showed significant increase in S.mutans plaque count after one month. After 3 months of chlorhexidine or Miswak application, chlorhexidine showed the least S.mutams count in plaque, followed by Miswak, while the control group had the highest bacterial count in plaque. (Table 1)

Both Chlorhexidine and control groups did not show a significant change in S.mutans plaque counts after 3 months when compared to the 1 month testpoint. Chlorhexidine showed an ability to keep S.mutans at a significantly lower counts compared to T1, however plaque S.mutans counts remained at high levels in the control group. In the Miswak group, the S.mutans plaque counts increased significantly after 3 months to levels equivalent to bacterial counts at $\mathrm{T} 1$ (Table 2).

Figure 3 shows S.mutans counts in plaque in the three study groups at different timepoints. 
Table 1. S.mutanscounts in plaque in the three study groups at different timepoints

\begin{tabular}{|c|c|c|c|c|}
\hline & $\begin{array}{c}\text { Chlorhexidine } \\
(\mathbf{n = 2 5})\end{array}$ & $\begin{array}{c}\text { Miswak } \\
(\mathbf{n = 2 5})\end{array}$ & $\begin{array}{c}\text { Control } \\
(\mathbf{n = 2 5})\end{array}$ & $\begin{array}{c}\text { One-way } \\
\text { ANOVA } \\
\text { P value }\end{array}$ \\
\cline { 2 - 5 } & \multicolumn{3}{|c|}{ Mean $\mathbf{\text { SD }}$} \\
\hline Baseline (T0) & $5.73 \pm 2.10$ & $5.88 \pm 2.73$ & $6.16 \pm 2.83$ & 0.83 \\
\hline $\begin{array}{c}\text { After bonding } \\
(\mathbf{T 1})\end{array}$ & $11.44 \pm 2.99$ & $11.34 \pm 2.30$ & $11.36 \pm 2.97$ & 0.99 \\
\hline One month (T2) & $7.66 \pm 2.48 \mathbf{a}$ & $7.85 \pm 2.63 \mathbf{a}$ & $13.34 \pm 3.10 \mathbf{b}$ & $<\mathbf{0 . 0 0 1 *}$ \\
\hline $\begin{array}{c}\text { Three months } \\
(\mathbf{T 3})\end{array}$ & $7.87 \pm 2.89 \mathbf{a}$ & $10.43 \pm 2.12 \mathbf{b}$ & $13.25 \pm 2.81 \mathbf{c}$ & $<\mathbf{0 . 0 0 1}^{*}$ \\
\hline $\begin{array}{c}\text { Repeated } \\
\text { measures ANOVA } \\
\text { P value }\end{array}$ & $<\mathbf{0 . 0 0 1 *}$ & $<\mathbf{0 . 0 0 1 *}$ & $<\mathbf{0 . 0 0 1 *}$ & \\
\hline
\end{tabular}

* Statistically significant at $\mathrm{p}$ value $<0.05$

a,b,c: different letters denote statistically significant differences between groups using Bonferroni adjusted significance levels

Table 2. S.mutans counts in plaque: post-hoc pairwise comparisons of different timepoints within each group

\begin{tabular}{|c|c|c|c|c|}
\hline \multirow{2}{*}{ Timepoint } & Compared to & $\begin{array}{c}\text { Chlorhexidine } \\
\text { P value }\end{array}$ & $\begin{array}{c}\text { Miswak } \\
\text { P value }\end{array}$ & $\begin{array}{c}\text { Control } \\
\text { P value }\end{array}$ \\
\hline \multirow{3}{*}{ T0 } & T1 & $<\mathbf{0 . 0 0 1 *}$ & $<\mathbf{0 . 0 0 1 *}$ & $<\mathbf{0 . 0 0 1 *}$ \\
\cline { 2 - 5 } & T2 & $\mathbf{0 . 0 2 *}$ & $\mathbf{0 . 0 0 9 *}$ & $<\mathbf{0 . 0 0 1 *}$ \\
\cline { 2 - 5 } & T3 & $\mathbf{0 . 0 2 *}$ & $<\mathbf{0 . 0 0 1 *}$ & $<\mathbf{0 . 0 0 1 *}$ \\
\hline \multirow{2}{*}{ T1 } & T2 & $<0.001 *$ & $<0.001 *$ & 0.10 \\
\cline { 2 - 5 } & T3 & $\mathbf{0 . 0 0 1 *}$ & 1.00 & 0.20 \\
\hline T2 & T3 & 1.00 & $\mathbf{0 . 0 0 8 *}$ & 1.00 \\
\hline
\end{tabular}

*Statistically significant differences between timepoints using Bonferroni adjusted significance levels 


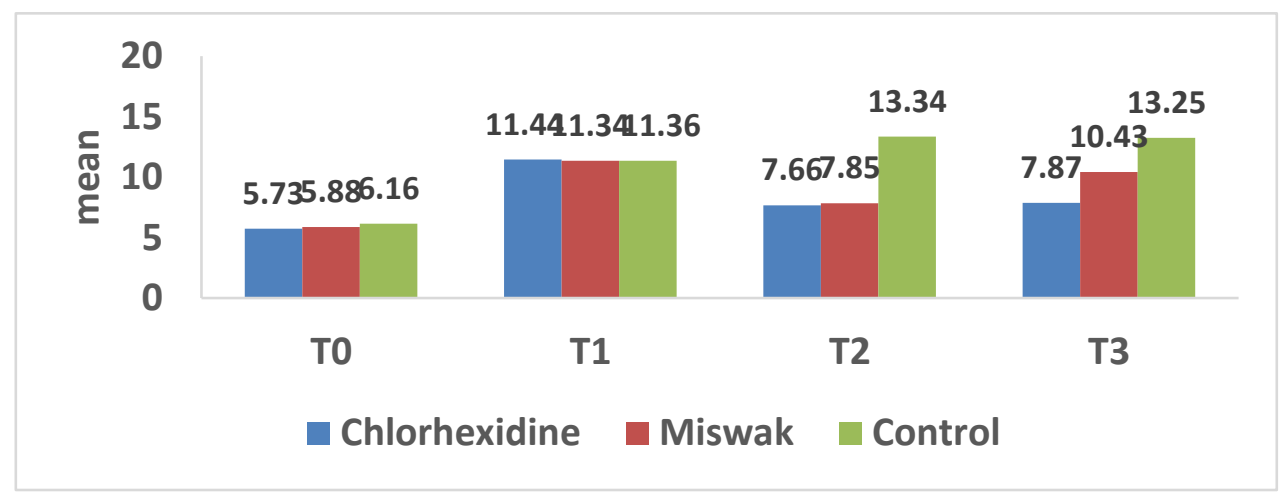

Figure 3. S.mutans counts in plaque in the three study groups at different timepoints

\section{S.mutans count in saliva:}

Except the significant increase in the salivary bacterial counts following fixed appliance bonding in all the study groups, no statistically significant differences were observed between the different study groups neither at the other timepoints nor within each group at different timepoints. (Table 3 and Table 4)

Table 3. S. mutans counts in saliva in the three study groups at different timepoints

\begin{tabular}{|c|c|c|c|c|}
\hline & $\begin{array}{c}\text { Chlorhexidine } \\
(\mathbf{n = 2 5})\end{array}$ & $\begin{array}{c}\text { Miswak } \\
(\mathbf{n = 2 5})\end{array}$ & $\begin{array}{c}\text { Control } \\
(\mathbf{n = 2 5})\end{array}$ & $\begin{array}{c}\text { One-way } \\
\text { ANOVA } \\
\text { P value }\end{array}$ \\
\cline { 2 - 5 } & \multicolumn{3}{|c|}{ Mean + SD } & 0.72 \\
\hline Baseline (T0) & $4.53 \pm 1.49$ & $4.57 \pm 1.47$ & $4.23 \pm 1.87$ & 0.56 \\
\hline $\begin{array}{c}\text { After bonding } \\
\text { (T1) }\end{array}$ & $6.03 \pm 1.96$ & $5.98 \pm 1.09$ & $6.44 \pm 1.73$ & 0.36 \\
\hline One month (T2) & $5.84 \pm 1.30$ & $5.93 \pm 1.48$ & $6.43 \pm 1.88$ & 0.08 \\
\hline Three months (T3) & $6.02 \pm 1.67$ & $5.66 \pm 1.65$ & $6.66 \pm 1.41$ & \\
\hline $\begin{array}{c}\text { Repeated } \\
\text { measures ANOVA } \\
\text { P value }\end{array}$ & $\mathbf{0 . 0 0 3 *}$ & $\mathbf{0 . 0 0 6 *}$ & $<\mathbf{0 . 0 0 1 *}$ & \\
\hline
\end{tabular}

* Statistically significant at $\mathrm{p}$ value $<0.05$

Table 4. S.mutans counts in saliva: post-hoc pairwise comparisons of different timepoints within each group

\begin{tabular}{|c|c|c|c|c|}
\hline \multirow{2}{*}{ Timepoint } & Compared to & $\begin{array}{c}\text { Chlorhexidine } \\
\text { P value }\end{array}$ & $\begin{array}{c}\text { Miswak } \\
\text { P value }\end{array}$ & $\begin{array}{c}\text { Control } \\
\text { P value }\end{array}$ \\
\hline \multirow{3}{*}{ T0 } & T1 & $\mathbf{0 . 0 1 *}$ & $\mathbf{0 . 0 0 1 *}$ & $\mathbf{0 . 0 0 1 *}$ \\
\cline { 2 - 5 } & T2 & $\mathbf{0 . 0 2 *}$ & $\mathbf{0 . 0 2 *}$ & $\mathbf{0 . 0 0 1 *}$ \\
\cline { 2 - 5 } & T3 & $\mathbf{0 . 0 3 *}$ & 0.22 & $<\mathbf{0 . 0 0 1 *}$ \\
\hline \multirow{2}{*}{ T1 } & T2 & 1.00 & 1.00 & 1.00 \\
\cline { 2 - 5 } & T3 & 1.00 & 1.00 & 1.00 \\
\hline \multirow{2}{*}{ T2 } & T3 & 1.00 & 1.00 & 1.00 \\
\hline
\end{tabular}

* Statistically significant differences between timepoints using Bonferroni adjusted significance levels 


\section{Gingival bleeding index (GBI):}

Both chlorhexidine and Miswak resulted in significantly lower GBI when compared to the control group at both one month and 3 months timepoints. However, no statistically significant differences were observed between chlorhexidine and Miswak neither at one month nor at 3 months timepoints. (Table 5)

Only chlorhexidine was able to reduce GBI significantly after one month, however, the GBI score was elevated again after 3 months to a level comparable to $\mathrm{T} 1$ score. Miswak did not reduce GBI score at T2 nor at T3. In the control group, the GBI score increased gradually to reach a significantly high score at T3. (Table 6).

An illustrative graph for GBI scores in the three study groups at different timepoints is shown in Figure 4.

Table 5. Gingival bleeding index in the three study groups at different timepoints

\begin{tabular}{|c|c|c|c|c|}
\hline & $\begin{array}{c}\text { Chlorhexidine } \\
(n=25)\end{array}$ & $\begin{array}{c}\text { Miswak } \\
(n=25)\end{array}$ & $\begin{array}{l}\text { Control } \\
(n=25)\end{array}$ & \multirow{2}{*}{$\begin{array}{c}\text { One-way } \\
\text { ANOVA } \\
\text { P value }\end{array}$} \\
\hline & \multicolumn{3}{|c|}{ Mean \pm SD } & \\
\hline Baseline (T0) & $0.283 \pm 0.06$ & $0.279 \pm 0.06$ & $0.277 \pm 0.06$ & 0.94 \\
\hline $\begin{array}{c}\text { After bonding } \\
\text { (T1) }\end{array}$ & $0.51 \pm 0.08$ & $0.52 \pm 0.09$ & $0.53 \pm 0.09$ & 0.85 \\
\hline One month (T2) & $0.46 \pm 0.07 \mathbf{a}$ & $0.47 \pm 0.09 \mathbf{a}$ & $0.60 \pm 0.08 \mathbf{b}$ & $<0.001 *$ \\
\hline $\begin{array}{c}\text { Three months } \\
\text { (T3) }\end{array}$ & $0.50 \pm 0.08 \mathbf{a}$ & $0.53 \pm 0.09 \mathbf{a}$ & $0.79 \pm 0.06 \mathbf{b}$ & $<0.001 *$ \\
\hline $\begin{array}{c}\text { Repeated } \\
\text { measures ANOVA } \\
\text { P value }\end{array}$ & $<0.001 *$ & $<0.001 *$ & $<0.001 *$ & \\
\hline
\end{tabular}

* Statistically significant at $\mathrm{p}$ value $<0.05$

a,b: different letters denote statistically significant differences between groups using Bonferroni adjusted significance levels

Table 6. Gingival bleeding index: post-hoc pairwise comparisons of different timepoints within each group

\begin{tabular}{|c|c|c|c|c|}
\hline Timepoint & Compared to & $\begin{array}{c}\text { Chlorhexidine } \\
\text { P value } \\
\end{array}$ & $\begin{array}{c}\text { Miswak } \\
\text { P value }\end{array}$ & $\begin{array}{l}\text { Control } \\
\text { P value }\end{array}$ \\
\hline \multirow{3}{*}{ T0 } & T1 & $<0.001 *$ & $<0.001 *$ & $<0.001 *$ \\
\hline & $\mathbf{T 2}$ & $<0.001 *$ & $<0.001 *$ & $<0.001 *$ \\
\hline & T3 & $<0.001 *$ & $<0.001 *$ & $<0.001 *$ \\
\hline \multirow{2}{*}{$\mathbf{T 1}$} & $\mathbf{T} 2$ & 0.009* & 0.69 & 0.06 \\
\hline & T3 & 1.00 & 1.00 & $<0.001 *$ \\
\hline $\mathbf{T 2}$ & T3 & 0.11 & $0.045 *$ & $<0.001 *$ \\
\hline
\end{tabular}

* Statistically significant differences between timepoints using Bonferroni adjusted significance levels 


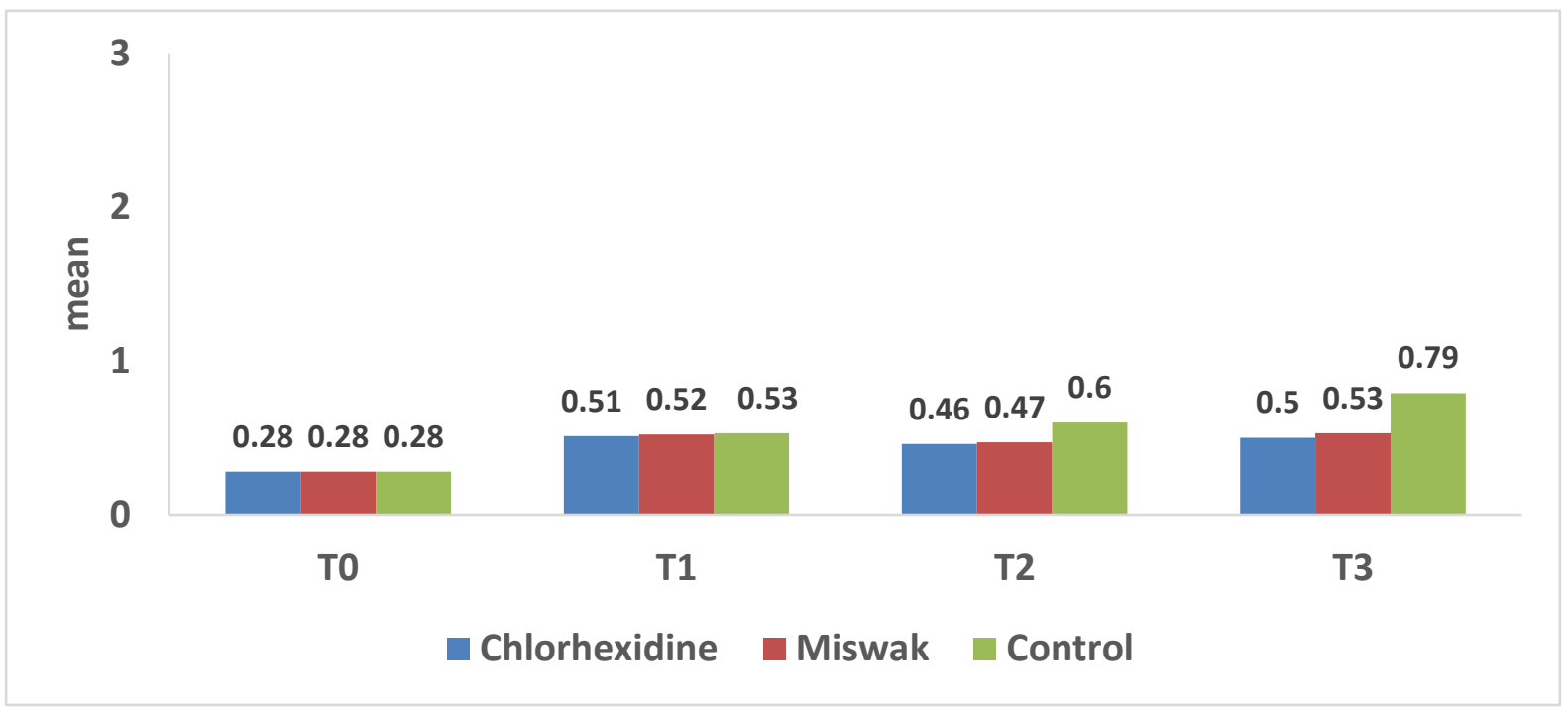

Figure 4. Gingival bleeding index in the three study groups at different timepoints

\section{Plaque index (PI):}

No statistically significant differences were observed between the 3 study groups at different timepoints. (Table 7).

However there was a decrease in PI from $\mathrm{T} 1$ to $\mathrm{T} 2$ in all the study groups, these differences were not significant. PI increased significantly from $\mathrm{T} 2$ to $\mathrm{T} 3$ in the 3 study groups. (Table 8).

Figure 5 illustrating PI in the three study groups at different timepoints.

Table 7. Plaque index in the three study groups at different timepoints

\begin{tabular}{|c|c|c|c|c|}
\hline & $\begin{array}{c}\text { Chlorhexidine } \\
\quad(n=25)\end{array}$ & $\begin{array}{c}\text { Miswak } \\
(n=25)\end{array}$ & $\begin{array}{c}\text { Control } \\
(n=25) \\
\end{array}$ & \multirow{2}{*}{$\begin{array}{c}\text { One-way } \\
\text { ANOVA } \\
\text { P value }\end{array}$} \\
\hline & \multicolumn{3}{|c|}{ Mean \pm SD } & \\
\hline Baseline (T0) & $1.12 \pm 0.32$ & $0.98 \pm 0.23$ & $0.96 \pm 0.20$ & 0.07 \\
\hline $\begin{array}{l}\text { After bonding } \\
\text { (T1) }\end{array}$ & $2.37 \pm 0.34$ & $2.36 \pm 0.38$ & $2.24 \pm 0.44$ & 0.45 \\
\hline One month (T2) & $2.16 \pm 0.47$ & $2.21 \pm 0.51$ & $2.17 \pm 0.42$ & 0.92 \\
\hline Three months (T3) & $2.82 \pm 0.22$ & $2.69 \pm 0.44$ & $2.73 \pm 0.42$ & 0.44 \\
\hline $\begin{array}{c}\text { Repeated } \\
\text { measures ANOVA } \\
\text { P value } \\
\end{array}$ & $<0.001 *$ & $<0.001 *$ & $<0.001 *$ & \\
\hline
\end{tabular}

$*$ Statistically significant at $\mathrm{p}$ value $<0.05$ 
Table 8. Plaque index: post-hoc pairwise comparisons of different timepoints within each group

\begin{tabular}{|c|c|c|c|c|}
\hline Timepoint & Compared to & $\begin{array}{c}\text { Chlorhexidine } \\
\text { P value }\end{array}$ & $\begin{array}{l}\text { Miswak } \\
\text { P value }\end{array}$ & $\begin{array}{l}\text { Control } \\
\text { P value }\end{array}$ \\
\hline \multirow{3}{*}{ T0 } & $\mathbf{T 1}$ & $<0.001 *$ & $<0.001 *$ & $<0.001 *$ \\
\hline & $\mathbf{T} 2$ & $<0.001 *$ & $<0.001 *$ & $<0.001 *$ \\
\hline & T3 & $<0.001 *$ & $<0.001 *$ & $<0.001 *$ \\
\hline \multirow{2}{*}{ T1 } & $\mathbf{T 2}$ & 0.20 & 1.00 & 1.00 \\
\hline & $\mathbf{T 3}$ & $<0.001 *$ & 0.11 & $0.002 *$ \\
\hline $\mathbf{T} 2$ & T3 & $<0.001 *$ & $0.001 *$ & $<0.001 *$ \\
\hline
\end{tabular}

*Statistically significant differences between timepoints using Bonferroni adjusted significance levels

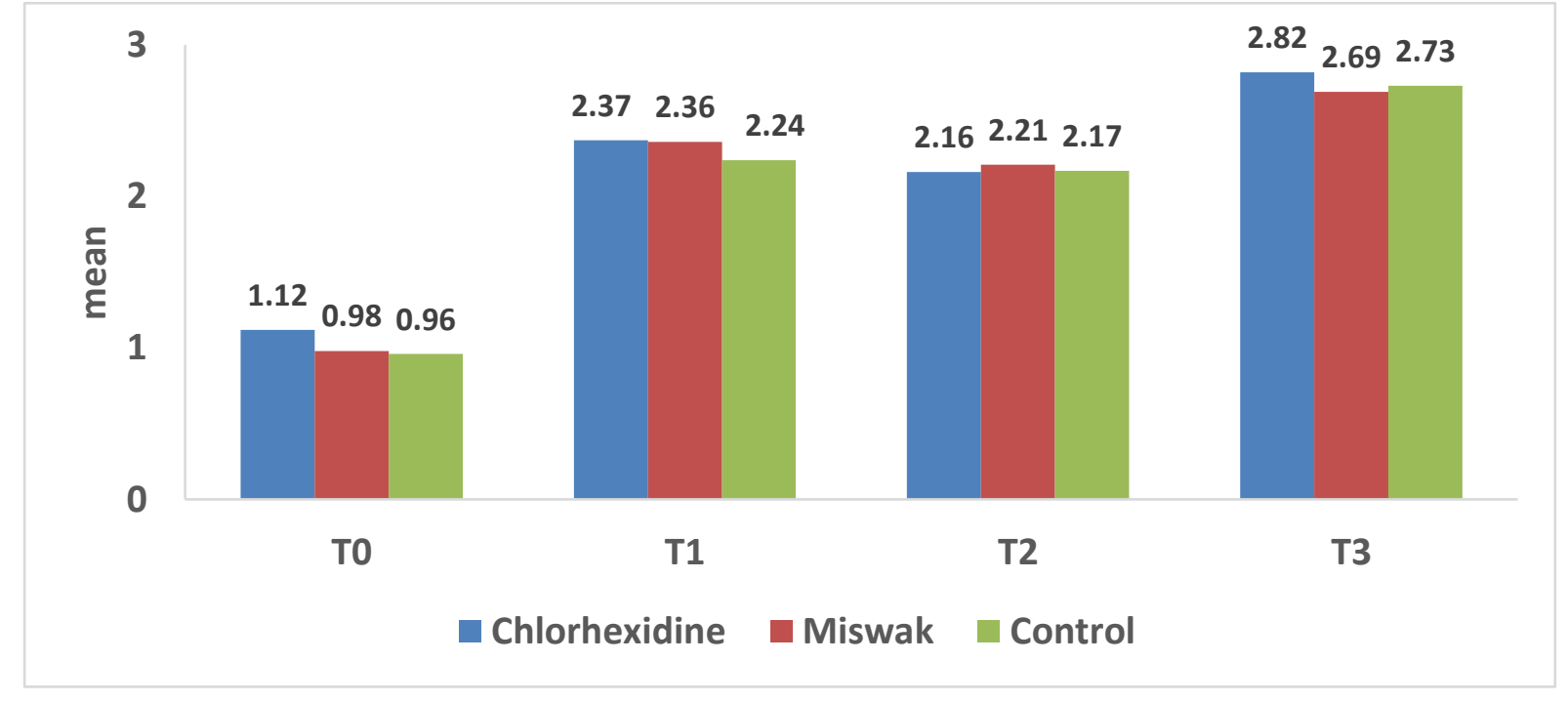

Figure 5. Plaque index in the three study groups at different timepoints

\section{$\underline{\text { Discussion }}$}

Orthodontic treatment is usually initiated in teenagers, who are known to have low compliance to oral hygiene instructions (38).Patients' compliance with the use of fluoridated mouthwashes during orthodontic treatment was less than 15\% (39). Moreover, the average time separating orthodontic followup visits is 4-6 weeks, making continuous monitoring of patients' oral hygiene difficult. This expected lack of oral hygiene during orthodontic treatment journey can cause permanent tooth damage and irreversible loss of tooth material caused by dental caries. Using a patient-independent method to decrease the levels of cariogenic bacteria could be beneficial to decrease the opportunity of such tooth damage during orthodontic treatment $(40,41)$.

The sample in this study consisted of females only, as females are more compliant and are co-operative following oral hygiene instructions efficiently than do males (42).

In the current study, Miswak varnish was prepared from aqueous extract. This allowed shorter periods of freeze drying and yielded greater amount of powder than if ethanolic extract was used (43). 
At T0, the baseline S.mutans count was recorded for each patient. Only participants who had moderate levels of initial S.mutans count (44) were included in the study. Studies that were performed in patients with initial high S.mutans counts did not find any significant differences in bacterial counts after chlorhexidine varnish application (41,45). However patients with low initial S.mutans counts sometimes yielded non-detectable levels of bacterial colonies (46).

In the current study, there was a significant increase in the S.mutams counts at T1; 2 weeks after the bonding of fixed orthodontic appliances. This finding is consistent with previous reports $(41,47,48)$. However a one week following fixed appliance bonding was enough for abundant plaque accumulation on teeth (49),(T1) was performed 2 weeks after fixed appliance bonding to allow for changes in the oral ecosystem to occur (40).

Unlike the control group that showed a continued elevation in S.mutans counts in plaque after 4 weeks, both chlorhexidine and Miswak varnishes resulted in significant decrease in S.mutans counts with no significant difference observed between chlorhexidine and Miswak varnishes after 4 weeks regarding S.mutans counts in plaque. This finding could suggest Miswak varnish as a valid natural substitute to chlorhexidine the gold standard in bacterial growth reduction and enamel demineraliziation inhibition (6).

After 3 months of fixed appliance bonding (T3), S.mutans counts tended to increase in the MV group, however, it remained significantly lower than the counts in the control group. However, plaque S.mutans counts remained low in the $\mathrm{CHX}$ group with no significant changes in bacterial counts from $\mathrm{T} 2$ to T3. This might suggest that a single application from Miswak varnish could reduce S.mutans counts efficiently for only 4 weeks.
On the other hand, the effect of a single application of chlorhexidine varnish on plaque S.mutans counts reduction could extend to 3 months. This finding comes in agreement with the literature that showed an extended antimicrobial effect resulting in lower $\mathrm{S}$. mutanscounts upto 3 months $(9,32,40)$ and even 6 months (50) following a single application of chlorhexidine varnish.

Neither chlorhexidine varnish nor Miswak varnish was able to reduce salivary S.mutans counts at any timepoint. This results comes in accordance with Ogaard et al (32) who found a significant decrease in plaque S.mutans counts with no effect on S.mutans counts in saliva. This finding could be explained that the effect of varnishes is a local effect confined to the area of application (teeth), and the active constitutes of the varnishes hardly could diffuse to produce a systemic or a widespread effect. Furthermore, salivary S.mutans were found to contain resistant strains more than plaque S.mutans did (51).

PI was used as a clue to the amount of plaque accumulated on individual's teeth, while GBI was used as an indication of gingival inflammation. Both indices give a good indication about oral hygiene status of the individual $(47,52)$. In the current study, a significant increase in plaque accumulation and gingival bleeding following bracket bonding was observed as described before in the literature (53). The results of the current study found that a single application of either chlorhexidine varnish or Miswak varnish resulted in statistically equal GBI and their effect extended for 3 months compared to the control group which showed significantly higher GBI scores at both T2 and T3. However there was no significant reduction in the GBI scores with either chlorhexidine or Miswak varnish, but the score did not increase as 
happened in the control group. This suggests comparable and extended effect of Miswak varnish relative to the chlorhexidine varnish in decreasing gingival inflammation associated with fixed orthodontic appliances (fig 2).

PI did not show significant changes in the 3 study groups from T1 to T2. However, it tended to increase significantly from T2 to T3 in all the study groups. The reason for increased plaque accumulation in orthodontic patients would be the increased number of plaque retentive areas and difficulty in reaching these areas by oral hygiene tools (53). However plaque accumulation was almost equal in the 3 study groups, gingival inflammation presented from GBI scores were always significantly higher in the control group compared to chlorhexidine and Miswak varnishes groups. An explanation for this would be that varnishes application (either chlorhexidine or Miswak) would change the quality regardless the quantity of the dental plaque with a change in its bacterial composition, making it less harmful.

Despite both tested varnishes significantly decreased S.mutans counts from $\mathrm{T} 1$ to $\mathrm{T} 2$, the clinical indices (GBI and plaque) did not show proportional significant reduction from T1 to T2. Previous reports (54-56) showed similar results where antimicrobial agents decrease S.mutans counts but did not affect plaque accumulation nor improved gingival indices. This would emphasize the importance of mechanical brushing/cleaning as an important element in oral hygiene measures for the maintenance of gingival health.

In all the test groups, the amount of accumulated plaque remained nearly the same in all the test groups from $\mathrm{T} 1$ to $\mathrm{T} 2$ and increased significantly from $\mathrm{T} 2$ to $\mathrm{T} 3$. This could be explained by the Hawthorne effect, as study subjects could change their daily behaviour or attitude because they know that they will be evaluated. At the first timepoint (T2), the patients were evaluated after one month from the start of the experiment. Patients at this timepoint were highly motivated and are impressed with the new situation of wearing braces. At the T3 timepoint (3 months from the bonding appointment), it is expected that patients could lose their starting motivation and start being reluctant following the oral hygiene instruction despite the efforts done by the investigators to emphasize on oral hygiene instruction on every follow-up appointment. The literature supports our findings and assumptions as a positive correlation was found between oral hygiene motivation and quantity of accumulated plaque and degree of gingival inflammation (57).

\section{Conclusions}

1. A single application of either chlorhexidine varnish or Miswak varnish significantly reduced S.mutans counts in plaque for 4 weeks of fixed appliance wear.

2. The antimicrobial effect of a single application of chlorhexidine varnish against S.mutans can extend at same efficiency upto 3 months. However, the antimicrobial efficiency of Miswak varnish against S.mutans decreased significantly after 3months.

3. Chlorhexidine varnish can be applied to teeth every 3 months to provide adequate anticariogenic effect, however, Miswak varnish can be an acceptable natural substitute to chlorhexidine varnish as an anticariogenic agent if applied at monthly basis.

4. A single application of Miswak varnish could reduce gingival inflammation upto 3 months in a manner comparable to a chlorhexidine varnish single application. 
5. Patient motivation for oral hygiene and monitoring of efficient mechanical brushing is mandatory to reduce plaque accumulation and maintain proper gingival health.

\section{References}

1. Bishara SE, Ostby AW. White Spot Lesions: Formation, Prevention, and Treatment. Semin Orthod. 2008;14(3):174-82.

2. Øgaard B, Rølla G, Arends J, ten Cate JM. Orthodontic appliances and enamel demineralization Part 2. Prevention and treatment of lesions. Am J Orthod Dentofac Orthop. 1988;94(2):123-8.

3. Bai L, Takagi S, Ando T, Yoneyama H, Ito $\mathrm{K}$, Mizugai $\mathrm{H}$, et al. Antimicrobial activity of tea catechin against canine oral bacteria and the functional mechanisms. J Vet Med Sci. 2016;78(9):1439-45.

4. Lalwani V, Koneru A, Vanishree M, Vardendra M, Hunasgi S, Surekha R. Antimicrobial activity of Punica granatum on streptococcus in dental caries patients and healthy individuals: A comparative study. J Adv Clin Res Insights. 2014;1(3):94-8.

5. Aravindraj S, Preethi M, Sivapathasundharam B. Antimicrobial Effects of Punica granatum Extracts on Staphylococcus aureus, Streptococcus mutans, Lactobacillus acidophilus, Enterococcus faecalis and Candida albicans. Int J Curr Microbiol Appl Sci. 2017;6(8):2762-74.

6. Balagopal S, Arjunkumar R. Chlorhexidine: The gold standard antiplaque agent. J Pharm Sci Res. 2013;5:270-4.

7. Rölla G, Melsen B. On the Mechanism of the Plaque Inhibition by Chlorhexidine. J Dent Res. 1975;54:57-62.

8. Ersin NK, Eden E, Eronat N, Totu FI, Ates M. Effectiveness of 2-year application of school-based chlorhexidine varnish, sodium fluoride gel, and dental health education programs in high-risk adolescents.
Quintessence Int. 2008;39(2):e45-51.

9. Zhang Q, Van Palenstein Helderman WH, Van't Hof MA, Truin GJ. Chlorhexidine varnish for preventing dental caries in children, adolescents and young adults: A systematic review Eur J Oral Sci; 2006;449-55.

10. Lipták L, Bársony $\mathrm{N}$, Twetman $\mathrm{S}$, Madléna M. The effect of a chlorhexidinefluoride varnish on mutans streptococci counts and laser fluorescence readings in occlusal fissures of permanent teeth: A split-mouth study. Quintessence Int. 2016;47(9):767-73.

11. Baygin $\mathrm{O}$, Tuzuner $\mathrm{T}$, Ozel $\mathrm{MB}$, Bostanoglu O. Comparison of combined application treatment with one-visit varnish treatments in an orthodontic population. Med Oral Patol Oral Cir Bucal 2013;18(2).

12. Gürgan CA, Zaim E, Bakirsoy I, Soykan E. Short-Term Side Effects of $0.2 \%$ Alcohol-Free Chlorhexidine Mouthrinse Used as an Adjunct to Non-Surgical Periodontal Treatment: A Double-Blind Clinical Study. J Periodontol. 2006;77(3):370-84.

13. Eriksen HM, Gjermo P. Incidence of stained tooth surfaces in students using chlorhexidine-containing dentifrices. Eur J Oral Sci. 1973;81(7):533-7.

14. Krzyściak W, Jurczak A, Kościelniak D, Bystrowska B, Skalniak A. The virulence of Streptococcus mutans and the ability to form biofilms. European Journal of Clinical Microbiology and Infectious Diseases. 2014 ;499-515.

15. Han X, Liu X, Bai D, Meng Y, Huang L. Nd:YAG Laser-aided ceramic brackets debonding: Effects on shear bond strength and enamel surface. Appl Surf Sci. 2008;255(2):613-5.

16. Banavar Ravi S, Nirupad S, Chippagiri P, Pandurangappa R. Antibacterial Effects of Natural Herbal Extracts on Streptococcus mutans: Can They Be Potential Additives in Dentifrices? Int J Dent. 2017;8:321-334. 
17. Chen F, Wang D. Novel technologies for the prevention and treatment of dental caries: A patent survey. Expert Opinion on Therapeutic Patents. Expert Opin Ther Pat; 2010:681-94.

18. Cruz Martínez C, Diaz Gómez M, Oh MS. Use of traditional herbal medicine as an alternative in dental treatment in Mexican dentistry: a review. Pharm Biol. 2017;55(1):1992-8.

19. Khatak M, Khatak S, Siddqui A, Vasudeva N, Aggarwal A, Aggarwal P. Salvadora persica Pharmacognosy Reviews. 2010:209-14.

20. Halawany HS. A review on miswak (Salvadora persica) and its effect on various aspects of oral health. Saudi Dental Journal. 2012;24:63-9.

21. Aumeeruddy MZ, Zengin G, Mahomoodally MF. A review of the traditional and modern uses of Salvadora persica L. (Miswak): Toothbrush tree of Prophet Muhammad Vol. 213, Journal of Ethnopharmacology. 2018;213:409-44.

22. Varma SR, Sherif H, Serafi A, Fanas SA, Desai V, Abuhijleh E, et al. The antiplaque efficacy of two herbal-based toothpastes: A clinical intervention. $J$ Int Soc Prev Community Dent. 2018;8(1):21-7.

23. Al-Ayed MSZ, Asaad AM, Qureshi MA, Attia HG, Almarrani AH. Antibacterial activity of Salvadora persica L. (Miswak) extracts against multidrug resistant bacterial clinical isolates. Evidence-based Complement Altern Med. 2016.

24. Al-Bayaty FH, Abdulla MA, Abu Hassan MI, Roslan SNB, Hussain SF, Bt Said HB. Effect of mouthwash extracted from Miswak (salvadora persica) on periodontal pathogenic bacteria an in-vitro study. International Conference on Science and Social Research. 2010:178-81.

25. Ezoddini-Ardakani F. Efficacy of
Miswak (salvadora persica) in preventing dental caries. Health. 2010;02:499-503.

26. Mohammed SG. Comparative study of in Vitro antibacterial activity of miswak extracts and different toothpastes. Am J Agric Biol Sci. 2013;8:82-8.

27. Darout IA, Albandar JM, Skaug N. Periodontal status of adult Sudanese habitual users of miswak chewing sticks or toothbrushes. Acta Odontol Scand. 2000;58:25-30.

28. Wu CD, Darout IA, Skaug N. Chewing sticks: Timeless natural toothbrushes for oral cleansing. J Periodontal Res. 200;36(5):27584.

29. Wassel MO, Khattab MA. Antibacterial activity against Streptococcus mutans and inhibition of bacterial induced enamel demineralization of propolis, miswak, and chitosan nanoparticles based dental varnishes. J Adv Res. 2017;8(4):387-92.

30. Silness J, Löe H. Periodontal disease in pregnancy II. Correlation between oral hygiene and periodontal condition. Acta Odontol Scand. 1964;22(1):121-35.

31. Ainamo J, Bay I. Problems and proposals for recording gingivitis and plaque. Int Dent J. 1975;25(4):229-35.

32. Øgaard B, Larsson E, Henriksson T, Birkhed D, Bishara SE. Effects of combined application of antimicrobial and fluoride varnishes in orthodontic patients. Am J Orthod Dentofac Orthop. 2001;120(1):28-35.

33. Syed SA, Loesche WJ. Survival of Human Dental Plaque Flora in Various Transport Media. Appl Environ Microbiol. 1972;24(4).

34. Möller AJ. Microbiological examination of root canals and periapical tissues of human teeth. Methodological studies. Odontol Tidskr. 1966;74(5):Suppl:1380 .

35. Gold OG, Jordan H V., van Houte J. A 
selective medium for Streptococcus mutans. Arch Oral Biol. 1973;18(11):1357-64.

36. EMILSON CG. Prevalence of Streptococcus mutans with different colonial morphologies in human plaque and saliva. Eur J Oral Sci. 1983;91(1):26-32.

37. Bratthall D. Immunofluorescent identification of Streptococcus mutans. Odontol Revy.1972;23(2):181-96.

38. Bakdash B. Current patterns of oral hygiene product use and practices. Periodontol 2000. 1995;8(1):11-4.

39. Geiger AM, Gorelick L, Gwinnett AJ, Benson BJ. Reducing white spot lesions in orthodontic populations with fluoride rinsing. Am J Orthod Dentofac Orthop. 1992;101(5):403-7.

40. Beyth N, Redlich M, Harari D, Friedman M, Steinberg D. Effect of sustainedrelease chlorhexidine varnish on Streptococcus mutans and Actinomyces viscosus in orthodontic patients. Am J Orthod Dentofac Orthop. 2003;123(3):345-8.

41. Jenatschke F, Elsenberger E, Welte HD, Schlagenhauf U. Influence of repeated chlorhexidine varnish applications on mutans streptococci counts and caries increment in patients treated with fixed orthodontic appliances. J Orofac Orthop. 2001;62(1):3645.

42. Sifakakis I, Papaioannou W, Papadimitriou A, Kloukos D, Papageorgiou SN, Eliades T. Salivary levels of cariogenic bacterial species during orthodontic treatment with thermoplastic aligners or fixed appliances: a prospective cohort study. Prog Orthod. 2018;19(1).

43. Balto H, Al-Sanie I, Al-Beshri S, Aldrees A. Effectiveness of Salvadora persica extracts against common oral pathogens. Saudi Dent J. 2017;29(1):1-6.

44. Attin R, Ilse A, Werner C, Wiegand A, Attind T. Antimicrobial effectiveness of a highly concentrated chlorhexidine varnish treatment in teenagers with fixed orthodontic appliances. Angle Orthod. 2006;76(6):1022-7.

45. Lundstrom F, Krasse B. Caries incidence in orthodontic patients with high levels of Streptococcus mutans. Eur J Orthod.1987;9(2):117-21.

46. Saruttichart T, Chantarawaratit PO, Leevailoj C, Thanyasrisung P, Pitiphat W, Matangkasombut $O$. Effectiveness of a motionless ultrasonic toothbrush in reducing plaque and gingival inflammation in patients with fixed orthodontic appliances. Angle Orthod. 2017;87(2):279-85.

47. Ogaard B, Larsson E, Glans R, Henriksson T, Birkhed D. Antimicrobial effect of a chlorhexidine-thymol varnish (Cervitec) in orthodontic patients. A prospective, randomized clinical trial. J Orofac Orthop. 1997;58(4):206-13.

48. Lucchese A, Bondemark L, Marcolina M, Manuelli M. Changes in oral microbiota due to orthodontic appliances: a systematic review. Journal of Oral Microbiology. 2018 ;6:547-558

49. Sukontapatipark W, El-Agroudi MA, Selliseth NJ, Thunold K, Selvig KA. Bacterial colonization associated with fixed orthodontic appliances. A scanning electron microscopy study. Eur J Orthod. 2001;23(5):475-84.

50. Huizinga ED, Ruben JL, Arends J. Chlorhexidine and thymol release from a varnish system. J Biol Buccale. 1991;19(4):343-8.

51. Trahan L, Soderling E, Drean MF, Chevrier MC, Isokangas P. Effect of xylitol consumption on the plaque-saliva distribution of mutans streptococci and the occurrence and long-term survival of xylitol-resistant strains. J Dent Res. 1992;71(11):1785-91.

52. Olympio KPK, Bardal PAP, De JR, Buzalaf MAR. Effectiveness of a chlorhexidine dentifrice in orthodontic patients: A 
randomized-controlled trial. J Clin Periodontol. 2006;33(6):421-6.

53. Naranjo AA, Triviño ML, Jaramillo A, Betancourth M, Botero JE. Changes in the subgingival microbiota and periodontal parameters before and 3 months after bracket placement. Am J Orthod Dentofac Orthop. 2006;130(3):275.e17-275.e22.

54. Bergamo AZN, de Oliveira $\mathrm{KMH}$, Matsumoto MAN, do Nascimento C, Romano FL, da Silva RAB, et al. Orthodontic appliances did not increase risk of dental caries and periodontal disease under preventive protocol. Angle Orthod. 2019;89(1):25-32.
55. Söderling E, Trahan L, TammialaSalonen T, Häkkinen L. Effects of xylitol, xylitol-sorbitol, and placebo chewing gums on the plaque of habitual xylitol consumers. Eur J Oral Sci. 1997;105(2):170-7.

56. Sari E, Birinci I. Microbiological evaluation of $0.2 \%$ chlorhexidine gluconate mouth rinse in orthodontic patients. Angle Orthod. 2007;77(5):881-4.

57. Ay ZY, Sayin MÖ, Özat Y, Goster T, Atilla AO, Bozkurt FY. Appropriate oral hygiene motivation method for patients with fixed appliances. Angle Orthod. 2007;77(6):1085-9. 